\title{
Clinical profile of Jatropha Curcas poisoning in children
}

\author{
Kosam A ${ }^{1}$, Nahrel $\mathbf{R}^{2}$ \\ ${ }^{1}$ Dr Ajay Kosam, Assistant Professor, ${ }^{2}$ Dr Rakesh Nahrel, Associate Professor. Both are affiliated with Department of \\ Pediatrics, Chhattisgarh Institute of Medical Sciences, Bilaspur, Chhattisgarh, India.
}

Address for correspondence: Dr Ajay Kosam, Email: kosamajay@gmail.com

\begin{abstract}
Introduction: Jatropha curcas (Physic nut; Hindi - Ratanjot, Bagranda, Jungle Erandi) is a common plant found all over the world. Accidental poisoning is common in children. This study aimed to describe the clinical profile and outcome of children admitted for acute Jatropha poisoning at a tertiary care teaching hospital from 2004 -2013. Materials and methods: This is a 10 year retrospective descriptive study. Hospital charts of children (ages 1 year to 18 years or less) admitted in the pediatric unit from Jan 2004 to Dec 2013 was reviewed. Total of 169 cases of Jatropha curcas poisoning were reported. Clinical profile and outcome were described. Mean, summation, percentage and frequency distribution were used where applicable. Results: Total 169 cases were evaluated. Acute Jatropha poisoning was the commonest cause of poisoning in children constituting $31 \%$ of poisoning cases. Vomiting was the most common symptom present in all children followed by abdominal pain (58\%), weakness (21\%), dehydration (13\%) and diarrhea (11\%).Hypovolemia shock was documented in 6 children with acute Jatropha poisoning. All children required IV fluids, IV anti emetics and ORS. 4 $\%$ cases required IV fluid resuscitation \& oxygen supplementation due to hypovolemia shock. Conclusion: Most children who ingest Jatropha curcas seeds develop mild gastrointestinal symptoms but life threatening complications like hypovolemia shock can occur. Health care providers must recognize, assess and initiate appropriate management promptly to minimize the serious consequences that could endanger the lives of the patients.
\end{abstract}

Keywords: Jatropha, Poisoning, Ratanjot, Ricinoleic acid

\section{Introduction}

Jatropha curcas is a common plant found all over the world. Jatropha is a genus of approximately 175 succulent plants, shrubs and trees (some are deciduous, like Jatropha Curcas L.), from the family Euphorbiaceae. The name is derived from Greek (iatros $=$ physician and trophe $=$ nutrition), hence the common name physic nut. The other common names are Jungle Erandi, Ratanjot, Bagranda, purging nut tree and Barbados nut tree [1]. Though all parts of the plant are poisonous, seeds have the highest concentration of the toxin and are highly poisonous [2]. The poisonous property of the plant is mainly due to presence of toxalbumin called curcin and cyanic acid, related to ricinoleic acid [3]. Though the plant grows in wastelands, it is cultivated mainly for hedges. As these plants are grown as an ornament they will often be found in gardens and public areas and therefore will be easily accessible. Jatropha are fruit bearing and the seeds have a pleasant

Manuscript received: $22^{\text {nd }}$ Apr 2014

Reviewed: $25^{\text {th }}$ Apr 2014

Author Corrected: $10^{\text {th }}$ May 2014

Accepted for Publication: 20 ${ }^{\text {th }}$ May 2014

International Journal of Medical Research and Review taste, the plants are particularly attractive to children. Furthermore, studies show that children are more susceptible to Jatropha poisoning when they ingest the seeds of the plant [4-6]. Jatropha poisoning is one of the leading causes of poisoning in children in our region. Every year children are admitted at Chhattisgarh Institute of Medical Sciences hospital, one of the biggest referral centers in the Bilaspur district, due to acute Jatropha ingestion or what is locally known as "Ratanjot" ingestion. However in spite of its ubiquity and propensity to cause many adverse effects on accidental consumption; not much literature is available. We present here the largest number of cases of Jatropha poisoning ever reported in an attempt to shed light on the frequency, severity, clinical manifestations and management of Jatropha curcas poisoning.

\section{Materials and methods}

The descriptive method was used in the study by doing a 10 year retrospective analysis of inpatient charts from Jan 2004 to Dec 2013. The objective of the study was to describe the clinical profile and outcome of children 


\section{Research Article}

admitted for acute Jatropha poisoning at Chhattisgarh Institute of Medical Sciences hospital. Total of 169 pediatric patients with acute Jatropha poisoning were studied. Descriptive statistics was used for data analysis. This is the largest study on acute Jatropha poisoning in children in available literature. All relevant patient charts were identified. The study population was chosen with the following inclusion criteria: (1) age of 1 year old up to $\leq 18$ years at the time of admission, (2) admitted only due to acute Jatropha poisoning, and (3) inclusive date of admission is from the year 2004 to 2013.Exclusion criteria: adult age group.

\section{Results}

In the present study from the year 2004 to 2013, a total of 169 cases of acute Jatropha poisoning in children was reported. The year 2013 had the most admissions due to acute Jatropha poisoning i.e. 40 cases followed by 31 cases in the year 2009,28 cases in the year 2011 and 25 cases in the year 2008. An increase in number of cases was noted from year 2008 till 2013 (Bar Chart 1)

Bar Chart 1: Distribution of Acute Jatropha poisoning cases according to year

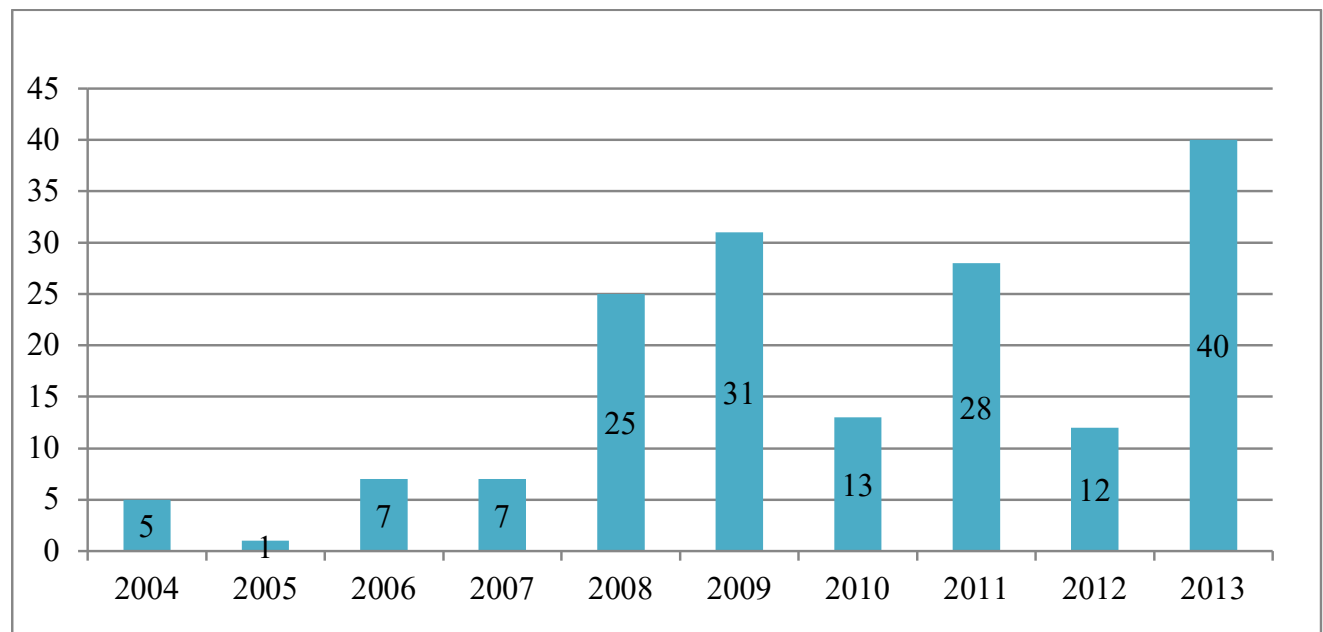

Most acute Jatropha poisoning in children happen during the months of November (31 cases), December (32 cases), January (42 cases) and March (29 cases). Occasional cases were also reported in other months (Bar Chart 2)

Bar Chart 2: Distribution of acute Jatropha poisoning cases according to month

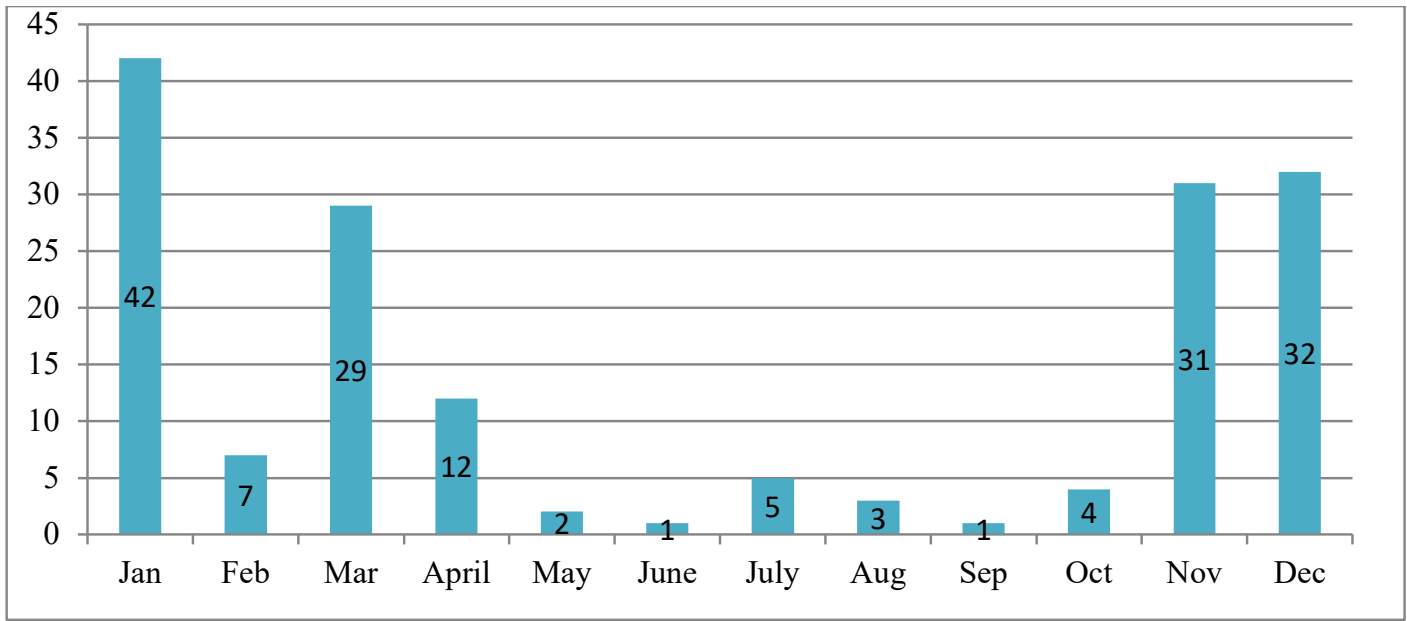

In the present study acute Jatropha poisoning was the commonest cause of poisoning in children constituting $31 \%$ (169/541) of poisoning cases admitted to our hospital followed by Kerosene ingestion constituting 20\% (112/541) and insecticide poisoning constituting $17 \%$ (94/541) of all poisoning cases 
$70 \%$ (118/169) of children with acute Jatropha poisoning were male with male female ratio of 2.3: $1.51 \%$ children were in age group of $6-12$ years and $37 \%$ children were between 3 to 6 years of age (Table 1). Youngest child was 1.5 years old and the oldest 13 years old.

Table 1: Socio-demographic variables of cases

\begin{tabular}{|c|c|c|}
\hline Demographic variable & No of cases & Percentage \\
\hline A. Gender & & 70 \\
Male & 118 & 30 \\
Female & 51 & 100 \\
\hline Total & 169 & 11 \\
\hline A. Age group & & 37 \\
$>3-3$ years & 18 & 51 \\
$>6-12$ years & 63 & 1 \\
\hline 12 years & 87 & 100 \\
\hline Total & 169 & \\
\hline
\end{tabular}

Vomiting was the most common symptom present in all children with acute Jatropha poisoning followed by abdominal pain $(58 \%)$, weakness (21\%), and dehydration (13\%). Diarrhea was present in only $11 \%$ children.

Hypovolemia shock was documented in 6 children with acute Jatropha poisoning. Most of the study populations were discharged within 24 hours. The rest were discharged after 24 hours. All cases were discharged with improved disposition (Table 2)

Table 2: Clinical profile of cases

\begin{tabular}{|c|c|c|}
\hline A.Signs and symptoms & No of cases & Percentage \\
\hline Vomiting & 169 & 100 \\
Signs of dehydration & 22 & 58 \\
Abdominal pain & 98 & 21 \\
Weakness & 36 & 11 \\
Diarrhea & 19 & 4 \\
Shock & 6 & 67 \\
\hline $\begin{array}{c}\text { B.Duration of hospital } \\
\text { confinement }\end{array}$ & 113 & 33 \\
\hline Moss than 24 hours & 56 & 100 \\
\hline Total & 169 & \\
\hline
\end{tabular}

In the present study all children with acute Jatropha poisoning required IV fluids, IV anti emetics and ORS. Gastric lavage was performed in only 39\% (66/169) cases. $4 \%$ (6/169) cases required IV fluid resuscitation \& oxygen supplementation due to hypovolemia shock (Table 3) 
Table 3: Management of cases

\begin{tabular}{|c|c|c|}
\hline Treatment given & No of cases & Percentage \\
\hline Gastric lavage & 66 & 39 \\
\hline ORS & 169 & 100 \\
\hline IV Fluids Maintenance & 169 & 4 \\
\hline Oxygen & 6 & 100 \\
\hline Anti emetic & 169 & 4 \\
\hline IV fluid resuscitation & 6 & 100 \\
\hline
\end{tabular}

Affected c

All children with acute Jatropha poisoning consumed seeds. The average numbers of seeds consumed were 3-4. Minimum number of seeds producing clinical manifestations of acute Jatropha poisoning was 1-2 seeds. In the present study maximum numbers of seeds consumed were $8-10$. The lag time before onset of symptoms varied between 30 minutes to 2 hours. Average recovery time was $5-6$ hours. There was no correlation between the number of seeds consumed and the severity of clinical manifestations. The la

\section{Discussion}

Jatropha curcas is a common plant found all over the world. Jatropha curcas originates from Central America. From the Caribbean, this plant was probably distributed to various other countries in Africa and Asia by Portuguese.

Today it is cultivated in almost all tropical and subtropical countries as protection hedges around gardens and fields, since it is not browsed by cattle.

Jatropha curcas L is a bush or small tree (up to $5 \mathrm{~m}$ height) and belongs to the euphorbia family. The genus Jatropha contains approximately 170 known species. The leaves of Jatropha curcas L are lobed, green and smooth. The flowers are small, yellow and are mostly hidden by the leaves. The stem is thick, green, glabrous becoming woody at the base.

The fruit is ovoid, oblong and contains 3 lobes with each lobe containing a seed. The fruit looks attractive (Figure - 1) and closely resembles cashew fruit though it bears no relationship to the latter.
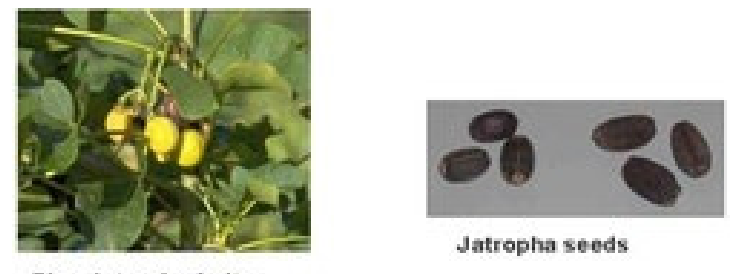

Ripe Jatropha fruits

Figure 1: Showing ripe Jatropha fruits and seeds
It is used for many medicinal purposes. In Homeopathy, it is used for cold sweats, colic, cramps, diarrhea etc. The yellow oil (also called Hell oil) is extracted from the seeds and is used for many medical conditions like eczema, herpes, indolent ulcers and chronic rheumatic pain. Medically it is used for purgation and as a styptic [7].The seeds of J. curcas have been used as a purgative, antihelminthic and abortifacient as well as for treating ascites, gout, paralysis and skin diseases.

The oil is also used for soap making, candle making and adulteration of olive oil. Nuts ground and mixed with palm oil are used as rat poison. Recently, the toxin (curcin) has been shown to have antitumor property [7].The latex of the plant has been shown to have haemostatic property [8].The leaf has been used as a haemostatic agent and the bark as a fish poison. In India, pounded leaves are applied near horses' eyes to repel flies. In our region the oil is used for lighting diya and lubricating cart wheel. Jatropha seed oil is being tried as a biofuel.

The Central Salt and Marine Chemicals Research Institute (CSMCRI), a Government-owned industrial research institute in India, is aiming to cultivate Jatropha plant for the production of biodiesel $[8,9]$. Jatropha oil is an environmentally safe, cost-effective, renewable source of non-conventional energy and a substitute for diesel, kerosene and other fuel oils. The oil can be mixed up to $50 \%$ and used for tractors and oil engines.

There have been few reports of toxicity due to Jatropha bean ingestion in the literature. None were fatal. This is 


\section{Research Article}

the largest study on acute Jatropha poisoning in the available literature. Stirpe et al [10], Rug and Ruppel [11] and Sudheer Pamidimarri et al [12] noted that because of its curcanoleic acid content which has been shown to produce severe gastrointestinal irritation in animals, symptoms of nausea, vomiting and diarrhea are common after ingestion. In more severe cases the gastrointestinal symptoms can last up to 72 hours [2]. Diarrhea can be particularly severe, necessitating constant intravenous hydration [2].

In our study the main reasons for admission due to Jatropha poisoning were vomiting, abdominal pain and weakness. Diarrhea was seen in only $11 \%$ cases. None of the patients had prolonged gastrointestinal symptoms. This can be explained by gastric irritation causing early onset of vomiting thereby reducing the local and systemic effect of toxins.

$6 / 169(4 \%)$ children in the present study developed hypovolemia shock due severe vomiting requiring IV fluid resuscitation and oxygen supplementation. This finding has not been reported in any other study suggesting that severe poisoning may be life threatening if not managed promptly.

Most cases of acute Jatropha poisoning in children were documented during the months of November, December and January which is the fruit-bearing season of Jatropha curcas hence, its accessibility and availability. According to age group, $88 \%$ children study population belongs to the preschool and school age group. Jatropha plant is very common in and about towns, sub urban areas and villages in thickets and hedges along roadsides. Children usually pass them on their way to school and alongside play areas. They are attractive to children, having a pleasant taste. $70 \%$ children were boys implying boys getting easily attracted to their flowers and plants and their natural tendency to experimentation.

All the children had consumed Jatropha seeds. The reasons cited by children for consuming seeds were attractive looks, pleasant taste and resemblance to groundnut. One interesting note is that in our report and in all reports from the literature, Jatropha bean ingestion often involved multiple victims [2, 4-6, 13, 14].The fact that the children concerned are older, school-aged children as well as preschool children suggests that the ingestion is a result of curiosity and exploration. The youngest child involved in acute Jatropha poisoning was 18 month old. $11 \%$ children were below 3 years of age. The younger children were also involved because they were given Jatropha beans by the older children rather than excessive hand-to-mouth activity normally observed with poisoning in younger children.

The other principal toxin in the seeds can be seen even after the oil has been extracted is a toxalbumin, curcin, which can inhibit protein synthesis and is hepatotoxic [1].Curcin has been shown to be 1,000 times less potent than ricin. Levin et al [2] reported mild elevation of transaminases and the delay can be up to 4 days. In our series none of the cases showed elevated liver enzymes. This can be explained by low potency of curcin to induce liver dysfunction.

U Kohli et al [15] documented kerosene poisoning as the commonest cause of poisoning in children followed by drugs and insecticides. S K Gupta et al [16] reported house hold products as the commonest cause of poisoning followed by drugs, industrial chemicals and insecticides. In our study acute Jatropha poisoning was the commonest cause of poisoning in children constituting $31 \%$ of all poisoning cases followed by kerosene poisoning $20 \%$ and insecticide poisoning $17 \%$. This finding highlights the importance of acute Jatropha poisoning and plant product poisoning to community and medical personnel's. This high incidence of plant poisoning in our study could be due to Jatropha plantation in our region and population being sub urban and rural with easy access to plants and trees.

The dose ingested is a major concern for physicians consulting the poison center. The children in our case series ingested up to $8-10$ seeds with no permanent injury. Minimum number of seeds producing signs of toxicity was 1-2.The children who developed hypovolemic shock had ingested an average of $4-5$ seeds whereas some children consuming 8 - 10 seeds had mild symptoms. There seemed to be no direct doseresponse relationship between the number of seeds ingested and symptom severity.

The poisonous property of the plant is mainly due to presence of toxalbumin called curcin, ricin and cyanic acid, related to ricinoleic acid [3].Ricin has been shown to exhibit many cardiotoxic and hemolytic effects. Though all parts of the plant are poisonous, seeds have the highest concentration of ricin and thus highly poisonous. The adverse effects following consumption of seeds include vomiting, diarrhea, abdominal pain and burning sensation in the throat. Within fifteen minutes of consumption vomiting and diarrhea set in. Acute abdominal pain is experienced about a half hour after the ingestion of the seeds. Although the available 
literature is scarce but all the Jatropha poisoning victims reported so far have been in the pediatric age group and all were presented with gastrointestinal manifestations.

However Koltin et al [17] reported that miosis is also a presenting sign of Jatropha intoxication. The combination of vomiting, diarrhea and miosis resembles the clinical presentation of organophosphate poisoning. This fact warrants the consideration of Jatropha ingestion in the differential diagnosis of organophosphate ingestion. In our study miosis was not documented in any child with acute Jatropha poisoning suggesting that miosis is not a consistent feature of acute Jatropha poisoning.

Human deaths by this plant have not been reported so far though animal deaths can occur. A systemic study by Abdu-Aguye et al [4] had clearly demonstrated the toxic effects of seeds when the extract of the dried seeds was administered intraperitoneally into mice. Post-mortem studies in this case showed widespread hemorrhages involving the colon, lungs as well as infarction of the liver. In another study by Adam et al [18] eleven Nubian goats were fed with Jatropha curcas seeds and fatal consequences were seen within 2 to 21 days.

Their Post-mortem examination revealed hemorrhage in the rumen, reticulum, kidney, spleen and heart, catarrhal or hemorrhagic enteritis, congestion and edema of the lung and excessive fluid in serous cavities.

Treatment is essentially symptomatic and supportive. In all cases of ingestion or suspected ingestion, if possible induce emesis within 1-2 hours of ingestion with Ipecac Syrup or perform gastric lavage when ingestion is recent (within one hour) and activated charcoal be given for all cases where time of ingestion is $<4$ hours and a cathartic to hasten elimination. . Many patients may not be able to tolerate activated charcoal if they already have nausea and vomiting. There is no specific antidote for it. Specific therapy may be indicated for hemorrhagic gastrointestinal damage, skeletal muscle and gastrointestinal spasm, excessive salivary secretions and hemoglobinuria.

After substantial exposures to toxalbumin containing plants, minimum observation period of up to 8 hours is advised. Give IV fluids and electrolyte as necessary to restore and maintain fluid and electrolyte balance. Monitor renal function and alkalinize urine to minimize effects of hemoglobinuria. Treat hemorrhagic gastrointestinal damage as for peptic ulceration. Observe for signs of CNS depression and initiate assisted ventilation if necessary.
Patient outcomes, both in our case series and in the reported literature, were favorable. No permanent sequel or major morbidity was reported. Majority of the study population was discharged improved less than or equal to 24 hours probably due to mild poisoning. Although Jatropha curcas ingestion can cause severe gastrointestinal symptoms, it is not associated with major morbidity or mortality.

\section{Conclusion}

Acute Jatropha poisoning is the most common cause of poisoning in children in Bilaspur district of Chhattisgarh due to its cultivation for biodiesel production and plantation along roadsides. With increase in the cultivation of Jatropha curcas for its use as biofuel there is an increase in accidental poisoning cases.

Though most children who ingested Jatropha seeds developed mild gastrointestinal symptoms but life threatening hypovolemic shock can occur in some children.

There is a general lack of awareness among medical professionals about its potential for serious toxicity. The main objective of this article is to make the practitioners and general population aware of the potential dangers of Jatropha Curcas seeds so as to minimize the accidental pediatric poisoning emergencies and financial burden on the community. Simultaneously school children, especially in rural areas, should be taught in schools to avoid experimentation with unfamiliar plant substances and household chemicals [19].

\section{Funding: Nil}

\section{Conflict of interest: Nil}

\section{Permission from IRB: Yes}

\section{References}

1. Barceloux DG. Barbados nut (Jatropha curcas L.) Medical toxicology of natural substances: foods, fungi, medicinal herbs, plants and venomous animals. Hoboken, New Jersey: John Wiley \& Sons Inc; 2008 Chapter 140; p.829-831.

2. Levin Y, Sherer Y, Bibi H, Schlesinger M, Hay E. Rare Jatropha multifida intoxication in two children. $\mathrm{J}$ Emerg Med 2000 Aug; 19(2):173-175.

3. Perri LM. Medicinal Plants of East and South East Asia. Cambridge London: MIT press; 1980; p. 246-247. 
Research Article

4. Abdu-Aguye I, Sannusi A, Alafiya-Tayo RA, Bhusnurmath SR. Acute toxicity studies with Jatropha curcas L. Hum Toxicol 1986 Jul;5(4):269-274.

5. Kulkarni ML, Sreekar H, Keshavamurthy KS, Shenoy N. Jatropha curcas poisoning. The Indian J Pediatr 2005 Jan; 72(1): 75-76.

6. Joubert PH, Brown JM, Hay IT, Sebata PD. Acute poisoning with Jatropha curcas (purging nut tree) in children. S Afr Med J 1984 May; 65 (18): 729-730.

7. Watt JM, Breyer-Brandwijk MG. The medicinal and poisonous plants of southern and eastern Africa. 2nd ed. Edinburgh, London: E. \&S. Livingstone Ltd; 1962.

8. Berchmans HJ, Hirata S. Biodiesel production from crude Jatropha curcas L. seed oil with a high content of free fatty acids. Bioresour Technol 2008 Apr; 99 (6): 1716-1721.

9. Patil PD, Deng S. Optimization of biodiesel production from edible and non-edible vegetable oils. Fuel 2009 Jul; 88(7): 1302-1306.

10. Stirpe F, Pession-Brizzi A, Lorenzoni E, Strocchi P, Montanaro L, Sperti S. Studies on the proteins from the seeds of Croton tiglium and of Jatropha curcas. Toxic properties and inhibition of protein synthesis in vitro. Biochem J 1976 Jan; 156 (1): 1-6.

11. Rug M, Ruppel A. Toxic activities of the plant Jatropha curcas against intermediate snail hosts and larvae of schistosomes. Trop Med Int Health 2000 Jun; 5 (6): 423-430.
12. Pamidimarri DVNS, Singh S, Mastan SG, Patel J, Reddy MP. Molecular characterization and identification of markers for toxic and non-toxic varieties of Jatropha curcas L. using RAPD, AFLP and SSR markers. Mol Biol Rep 2009 Jul; 36 (6): 13571364.

13. Menezes RG, Rao NG, Karanth SS, Kamath A, Manipady S, Pillay VV. Jatropha curcas poisoning. Indian J Pediatr 2006 Jul; 73(7): 634.

14. Rai DK, Lakhanpal P. Jatropha curcas poisoning in pediatric patients, Mauritius. Internet J Pediatr Neonatal 2008 Mar; 8 (2): 1-6.

15. Kohli U, Kuttiat VS, Lodha R, Kabra SK. Profile of Childhood Poisoning at a Tertiary Care Centre in North India. Indian J Pediatr 2008 Jun; 75 (8): 791-794.

16. Gupta SK, Peshin SS, Srivastava A, Kaleekal T. A study of childhood poisoning at National poisons information centre, AIIMS, New Delhi.J Occup Health 2003 May; 45(3): 191-196.

17. Koltin D, Uziel Y, Schneidermann D, Kotzki S, Wolach B, Fainmesser P. A case of Jatropha multifida poisoning resembling organophosphate intoxication. Clin Toxicol (Phila). 2006 Mar; 44(3):337-338.

18. Adam SE, Magzoub M. Toxicity of Jatropha curcas for goats. Toxicology $1975 \mathrm{Jul}$; 4(3): 347-354.

19. Lall SB. Accidental pediatric poisoning - a preventable medical emergency (Editorial). Indian $\mathrm{J}$ Pediatr 1998 May- Jun; 65(3): 365-370.

\section{How to cite this article?}

Kosam A, Nahrel R. Clinical profile of Jatropha Curcas poisoning in children. Int J Med Res Rev 2014;2(3):221- 227. doi:10.17511/ijmrr.2014.i03.12. 